\title{
ARTICLE
}

\section{Interventions for challenging behaviour in intellectual disability}

\author{
Afia Ali, Jessica Blickwedel \& Angela Hassiotis
}

\begin{abstract}
Afia Ali has recently completed her higher training in the psychiatry of intellectual disability and a Medical Research Council clinical training fellowship during which she completed a PhD at University College London. Jessica Blickwedel is a research assistant at University College London and is involved in a randomised controlled trial of positive behavioural support in people with intellectual disability. Angela Hassiotis is a reader in intellectual disability at University College London and an honorary consultant with Camden and Islington NHS Foundation Trust. She has published research on clinical trials of challenging behaviour in people with intellectual disability and is the lead author of a Cochrane review on psychological interventions for aggressive behaviour in people with intellectual disability. She is a member of the NICE Guideline Development Group on Challenging Behaviour in Learning Disability. Correspondence Dr Afia Ali, Mental Health Sciences Unit, University College London, 2nd Floor, Charles Bell House, 67-73 Riding House, London W1W 7EY, UK. Email: afia.ali@ucl.ac.uk
\end{abstract}

\begin{abstract}
SUMMARY
Challenging behaviour is common in intellectual disability but it is difficult to diagnose and manage. It can adversely affect the quality of life of the individual and cause the breakdown of community placements, resulting in hospital admission. This article discusses the aetiology of challenging behaviour (including the complex relationship with mental illness), diagnostic problems, the current evidence base in relation to psychosocial and pharmacological treatments, and service delivery.

\section{LEARNING OBJECTIVES}

- Understand the aetiological basis of challenging behaviour.

- Understand the role of functional analysis.

- Appreciate the evidence base in relation to the psychological and pharmacological treatment of challenging behaviour.

\section{DECLARATION OF INTEREST}

A.A. was Trainee Editor on Advances in Psychiatric Treatmentwhen this article was written. She took no part in the decision to publish. A.H. is the chief investigator and J.B. a research assistant on a multicentre trial of positive behavioural supportfor people with intellectual disability presenting with challenging behaviour. The study is being funded by the National Institute for Health Research Health Technology Assessment Programme.
\end{abstract}

Challenging behaviour in individuals with intellectual disability is a complex but common problem that can present diagnostic and management challenges for healthcare professionals. All behaviour serves a purpose, has an origin and meaning, and is therefore produced by an interaction between an individual and their environment. Challenging behaviour is a socially constructed, dynamic concept in that for a displayed behaviour to be considered challenging another person will have interpreted it as being dangerous, frightening, distressing or annoying (Royal College of Psychiatrists 2007). Consequently, what is defined as challenging may vary across cultures or settings.

Clinically, challenging behaviour refers to persistent and pervasive maladaptive behaviour(s) that has a significant adverse effect on the quality of life and/or health and safety of the individual or others. The term can include a range of behaviours, for example physical aggression towards objects or people, self-injury, sexually inappropriate behaviour, offending behaviour (such as arson or stealing), mannerisms or rituals (Royal College of Psychiatrists 2007). If the behaviour threatens the quality of life or physical safety of others, it can result in the individual's exclusion from services or community activities or provoke restrictive and aversive responses that may be socially or morally unacceptable. Hence, trying to understand and, where appropriate, reduce the occurrence of challenging behaviour is of utmost importance. Challenging behaviour can be an attempt to communicate unmet needs, so strategies that are proactive and flexible in addressing these should be put in place, positive behavioural development should be promoted and the response of professionals and carers to challenging behaviour should be socially enabling rather than restricting (Royal College of Psychiatrists 2007).

\section{Epidemiology}

Reported prevalence of challenging behaviour in adults with intellectual disability varies depending on the definition used for ascertainment, study methodology, settings and populations. It has previously been reported to range between $6.1 \%$ in the community and 40\% in long-stay hospitals (Emerson 1995). In the total intellectual disability population the incidence of 'serious challenging behaviour' was found to be around 10\% (Lowe 2007) and that of any type of challenging behaviour was 10-15\% (Emerson 2001a). A community-based epidemiological study found a prevalence of $4.9 \%$ for self-injurious behaviour (Cooper 2009a) and of 9.8\% for aggression (Cooper 2009b). Challenging behaviour appears to be even more pervasive in individuals with profound intellectual disability and multiple disabilities, with a prevalence of $82 \%$ for self-injurious and stereotypical behaviour and $45 \%$ for aggressive/destructive behaviour (Poppes 2010).

In a meta-analytic study of markers of challenging behaviour in people with intellectual 
disability, aggressive behaviour was associated with male gender; self-injurious behaviour was more likely in those with severe or profound intellectual disability and those with receptive or expressive communication difficulties; and a diagnosis of autism was associated with self-injury, aggression and disruption to the environment (McClintock 2003).

\section{Aetiology}

The causes of challenging behaviour (Box 1 and Box 2) are complex and multifactorial, and should be understood from a biopsychosocial perspective. Biological factors contributing to challenging behaviour include genetic disorders associated with behavioural phenotypes (e.g. Prader-Willi syndrome and aggression; LeschNyhan syndrome and severe self-injury), physical illness (e.g. epilepsy) and associated symptoms such as constipation, pain, urinary incontinence and visual impairment (de Winter 2011), and side-effects of medication, including antiepileptics. Recent advances in genetics suggest that rare chromosomal abnormalities such as

\begin{tabular}{|c|c|}
\hline Cause & Examples \\
\hline \multirow{8}{*}{$\begin{array}{l}\text { Physical complaints and } \\
\text { symptoms }\end{array}$} & Constipation \\
\hline & Urinary tract infections \\
\hline & Otitis media/ear-ache \\
\hline & Respiratory infections \\
\hline & $\begin{array}{l}\text { Gastritis/gastro-oesophageal } \\
\text { reflux }\end{array}$ \\
\hline & Dental pain \\
\hline & Menstruation \\
\hline & Headache \\
\hline \multirow[t]{3}{*}{ Behavioural phenotypes } & Prader-Willi syndrome \\
\hline & Fragile-X syndrome \\
\hline & Lesch-Nyhan syndrome \\
\hline \multirow[t]{5}{*}{ Psychiatric disorders } & Psychotic disorders \\
\hline & Mood disorders \\
\hline & Anxiety disorders \\
\hline & Autism spectrum disorders \\
\hline & Hyperkinetic disorders \\
\hline \multirow{2}{*}{$\begin{array}{l}\text { Psychological or social } \\
\text { factors }\end{array}$} & Trauma/life events \\
\hline & Distress \\
\hline \multirow{4}{*}{$\begin{array}{l}\text { Behaviour serving a } \\
\text { function }\end{array}$} & To gain attention from carers \\
\hline & To avoid chores/activities \\
\hline & To obtain tangibles \\
\hline & For sensory reinforcement \\
\hline
\end{tabular}

\section{BOX 2 Challenging behaviour associated with a physical cause}

Annette has autism, severe intellectual disability and is non-verbal. She lives at home with her parents. Her mother reports that she has started to repetitively bang her head against the wall and to bite her hand. She has bruises on her head and deep injuries on her hand and arms. Her appetite has decreased and she has lost $12 \mathrm{~kg}$ in weight. She is also up at night, pacing up and down her room. Following discussion with her family, she is admitted, under Section 2 of the Mental Health Act 1983, to an assessment and treatment unit for people with intellectual disability. She refuses to have blood tests and investigations.

The initial working diagnosis was that of a depressive disorder and her psychiatrist started her on an antidepressant, but she failed to respond even when the dose was increased. A trial dose of risperidone was then initiated but had minimal effect. Owing to concerns about her physical health, and her lack of capacity to make decisions about her treatment, a best interests meeting was held to discuss whether an MRI of her brain and other investigations should be conducted under sedation. Her family and the professionals agreed that this was the best course of action. An MRI revealed that she had a brain tumour. She was urgently referred to the neurosurgeons and, following treatment under her best interests, she made a steady recovery over the next 6 months.

microdeletions or duplications may be associated with intellectual disability and challenging behaviour (Vissers 2010).

Psychological factors include psychological trauma, mental illness and neuropsychiatric disorders such as autism. Social factors may include family discord and economic deprivation (Emerson 2001b), negative life events (Esbenson 2006), bereavement (Dodd 2005) and communication difficulties.

Individuals often use challenging behaviour as a form of communication when they would like to gain access to a particular object or activity, or avoid or escape an activity or person (Fox 2000). It may also serve to communicate dissatisfaction with their environment or lack of support due to poorly trained staff or inadequately resourced day services.

\section{Challenging behaviour and mental illness}

The relationship between challenging behaviour and mental illness is complex and not fully understood (for a review see Thakker et al 2012). Mental illness is more common in people who exhibit challenging behaviour than in those who do not (Moss 2000). Several factors have 
${ }^{\dagger}$ Practical measures for improving communication are given in Boardman L, Bernal J, Hollins S (2014) Communicating with people with intellectual disabilities: a guid for general psychiatrists. Advances in Psychiatric Treatment, 20: 27-36. Ed. been suggested as potential causes of coexisting mental illness and challenging behaviour in people with intellectual disability. (Emerson 2001b). Challenging behaviour may be an atypical presentation of core symptoms of a specific disorder (e.g. self-injury such as repetitive skin picking may be part of an underlying obsessivecompulsive disorder); it may occur as a secondary feature of mental illness (e.g. self-injury and aggression may be a feature of depression); and it may be reinforced by the symptoms of a mental illness. More than one mechanism may contribute to challenging behaviour in some individuals.

\section{Diagnostic problems}

Establishing the cause of challenging behaviour is rarely straightforward. In particular, the diagnosis of mental illness in individuals with intellectual disability and challenging behaviour can pose significant problems for clinicians. For example, if the patient is unable to communicate, the clinician must rely on whether changes in biological symptoms (e.g. sleep and appetite) have occurred..$^{\dagger}$ Diagnosis of mental illness may also be complicated if atypical symptoms are present, or if there are inconsistencies in the reports given by informants (Moss 1999). The presence of autism may also complicate the presentation of psychiatric symptoms. Agitation and inappropriate sexual behaviour in a young man with autism may be mistaken for hypomania; a young woman with autism observed talking to herself or engaging in concrete thinking may be incorrectly diagnosed with psychosis. At times of stress, individuals with autism may also present with transient psychoticlike symptoms such as anxiety, thought disorder and persecutory ideas, particularly if they are asked to stop an activity that they are engaged in or asked to begin a new activity (Berney 2000).

Diagnostic overshadowing (Reiss 1982) may occur, meaning that a symptom or behaviour is attributed to the person's intellectual disability or environmental factors when it is in fact due to mental or physical illness (Palucka 2003).

\section{Assessment of challenging behaviour: functional analysis}

The initial stage of assessment of challenging behaviour involves gathering information about the problem behaviour from a number of sources, including the patient, relatives and paid carers. A detailed psychiatric history, mental state examination, physical examination and direct observations in a number of settings, alongside appropriate medical investigations, may reveal an underlying psychiatric or physical illness as the cause of the behaviour. Where there is no obvious underlying physical or psychiatric cause, the next stage requires a functional analysis of the behaviour.

In functional analysis, the individual and their environment are examined to determine what purpose the behaviour may be serving for the individual and what factors in the environment may increase or diminish the behaviour. There may be clear triggers for the behaviour, or factors that maintain or reinforce it. In addition, the behaviour may be more likely to occur in the presence of particular personal, biological or environmental aspects, referred to as 'setting events' (Bijou 1978). For example, tiredness, poor lighting or the number of people in the room may increase the likelihood of the behaviour (Carter 2007).

\section{Carrying out a functional analysis}

The process involved in carrying out a functional analysis is outlined in Box 3. Direct observations and baseline data about the frequency and duration of the behaviour are essential. Events and observed behaviour can be recorded on an ABC chart for subsequent analysis of the antecedents (A), behaviour (B) and associated consequences (C). In addition, questionnaires and rating scales such as the Motivation Assessment Scale (Durand 1992) may be used to gather information about the possible function of the behaviour. Ideally, the formulation should lead to an intervention or a further period of assessment and analysis, including manipulation of the antecedents or consequences (for a review see Hanley et al 2003). Any interventions that are implemented will need to be evaluated for effectiveness and modified if necessary.

A meta-analysis has shown that functional analysis is important in achieving a positive outcome of behavioural interventions for people with intellectual disability (Carr 1999).

\section{BOX 3 The process of functional analysis}

- Obtain a clear description of the behaviour

- Identify factors that predict whether the behaviour will or will not occur

- Identify the factors or consequences that maintain the behaviour

- Develop a hypothesis about the function of the behaviour

- Make direct observations that provide evidence supporting the hypothesis

(0’Neill 1997) 


\section{Management of challenging behaviour}

Approaches for managing challenging behaviour include psychosocial interventions as well as medication. A survey of psychiatrists suggested that non-pharmacological interventions are the first-choice treatment for aggression where no psychiatric condition is confirmed (Unwin 2008). The consensus was that pharmacological interventions are considered if other treatment is unsuccessful owing to the frequency or severity of the aggressive behaviour, or when there is a risk of harm to self or others. The evidence base for some of these treatment options will be considered here.

\section{Psychosocial interventions}

Numerous psychosocial interventions have been proposed to address challenging behaviour in people with intellectual disability and the available evidence base for these varies greatly between treatments. In this section we consider some of these treatments and the support for their efficacy.

\section{Social interventions}

Social interventions for challenging behaviour in people with intellectual disability can focus on a range of factors, including level of care, communication and environmental manipulation. For example, nidotherapy (Tyrer 2005) involves making systematic environmental changes (physical, social and personal) to suit the needs of the individual. The aim is to adapt the environment rather than trying to adapt the person. The environmental changes may include alterations to the structural environment, helping the individual to socialise or supporting them in achieving their long-term goals. Nidotherapy offers environmental adjustment rather than direct treatment and at present there is no evidence supporting its efficacy for challenging behaviour in people with intellectual disability (Tyrer 2007).

Active support is another type of social intervention that has been used with people with intellectual disability. Staff receive training in developing person-centred activity plans for those in their care and receive coaching on how to encourage them to engage in activities to deflect them from challenging behaviour. Trials (mainly small case studies) have shown contrasting results, including no effect (Jones 2001; Stancliffe 2008), a decrease in challenging behaviour (Toogood 2009) and an increase in challenging behaviour (Bradshaw 2004). Further evaluation of active support is warranted.

\section{Cognitive-behavioural therapy}

Cognitive-behavioural therapy (CBT) has only recently been adapted for people with intellectual disability. At present, evidence from methodologically sound studies is still scarce for its use as an intervention for challenging behaviour.

A Cochrane review of interventions for aggressive behaviour in people with intellectual (learning) disabilities identified just four studies, three using group-based and one using individual CBT with adults, as suitable for inclusion (Hassiotis 2008). Results were variable. Although improvement was reported in emotional distress, anger management and adaptive functioning on both caregiver- and self-ratings, the follow-up periods were short and the studies were subject to bias. More recently, the effectiveness of cognitivebehavioural interventions with this client group was tested in a cluster randomised controlled trial of a 12-week group-based cognitive-behavioural anger management programme delivered by care workers. The findings showed no effect in selfreported anger, but significant improvement in anger as rated by paid and family carers (Willner 2013). The study also demonstrated that the intervention may be delivered by less-qualified staff with reasonable fidelity.

Therefore, at present, there is some limited support for the use of CBT as an intervention for challenging behaviour in people with intellectual disability, but further evaluation is necessary.

\section{Mindfulness}

Mindfulness, which has its origins in Buddhism, has been described as the focusing of one's attention on present experiences with curiosity, openness and acceptance (Bishop 2004). It has been used for a range of clinical problems and can be used both in conjunction with or as an alternative to behavioural approaches. Mindfulness-based interventions have consistently reported positive outcomes in modifying behaviour. A review evaluating the evidence to date (Harper 2013) identified 18 studies that used mindfulness either as a stand-alone intervention or as part of acceptance and commitment therapy or dialectical behaviour therapy. Ten of these studies recorded effects on aggressive behaviour and all ten reported reduction in aggression. Some of the other positive effects included a reduction in self-injury and injury to staff, reduced self-reports of deviant sexual arousal and a decrease in the management of aggression using medication and restraints by staff. Notably, evidence gained from five of the reviewed studies also suggests that caregivers could successfully be trained 
BOX 4 Features of positive behavioural support

- The goal is to enhance quality of life by improving community participation, choice and personal competence in addition to behavioural change

- A functional analysis is conducted to understand the purpose of the behaviour

- The intervention attempts to alter the triggers of a behaviour (including setting events) in order to reduce the likelihood of it occurring

- Skills teaching is a central component and includes teaching communication skills and coping skills

- The intervention has a multi-component focus, reflecting that multiple types of challenging behaviour may be present

- No punishment is used

- Reinforcement is used to maintain good behaviour

- Both reactive and proactive strategies are incorporated

- The intervention instigates changes in carers' behaviour and how services are delivered

to deliver mindfulness-based interventions. However, all the studies were open label and none included comparison with placebo or another control group. Further support is needed in the form of randomised controlled trials and larger samples in order to establish more conclusive evidence regarding the use of mindfulness in the management of challenging behaviour.

Applied behavioural analysis and positive behavioural support

In essence, the science of applied behavioural analysis involves systematically addressing challenging behaviour using principles of reinforcement and extinction. Since its introduction in the 1960s, the effectiveness of applied behavioural analysis has been illustrated in a large volume of work, including more than 600 studies in the Journal of Applied Behavior Analysis alone. One of the more recent studies found that its use by a specialist behaviour therapy team, in addition to standard treatment, produced a significant reduction in challenging behaviour measured by the Aberrant Behavior Checklist and that this positive change was maintained at 2-year followup (Hassiotis 2009, 2011).

In its original form, applied behavioural analysis used a range of non-aversive and aversive techniques, but in response to increasing criticism the aversive procedures were abandoned. In the 1980s, applied behavioural analysis took a more person-centred, values-led direction.
This is reflected in techniques such as 'positive behavioural support', an approach that continues to evolve (Carr 2002).

Positive behavioural support (Box 4) involves identifying the purpose of the challenging behaviour and working out a support plan that encourages the development of new skills to reduce the individual's need to engage in the behaviour (Carr 2002; Allen 2005). Its focus is on individualised interventions that are based on a clear understanding of the person and the purpose of the behaviour. The interventions aim to develop appropriate social, communication and behavioural skills that enable the individual to replace the problem behaviour with a functionally equivalent behaviour that is more appropriate. It avoids the use of aversive measures such as punishment (e.g. excluding the individual from certain activities) and promotes the use of positive and supportive strategies. The overall aim is to improve the individual's quality of life by enabling them to have positive social interactions and access new environments (Box 5).

Positive behavioural support can be delivered by diverse mediators, ranging from family members to support workers, but mediators will need to receive training and to be appropriately organised and supported (Royal College of Psychiatrists 2007).

BOX 5 Using positive behavioural support to alter behaviour

James has a severe intellectual disability and is nonverbal. He lives in a residential home. His carers reported concerns about his aggressive behaviour towards staff and other residents. He was referred to a clinical psychologist and a functional analysis of his behaviour was conducted. $A B C$ charts revealed that triggers to his behaviour included being asked to share the television with other residents or to carry out a chore such as tidying his room. When such demands were made, he shouted and screamed at staff, threw objects and pushed and hit staff and other residents. Staff responded to his behaviour by allowing him to watch the television on his own and allowing him to escape his chores. It was noted that his behaviour was worse after an epileptic seizure or if he had not been sleeping well at night. A hypothesis was developed that the function of his behaviour was to avoid or escape demands and that staff were reinforcing the behaviour by allowing him to avoid tasks. A positive behaviour support plan was developed whereby he was taught to hold up a card to indicate that it was his turn to watch the television and he would then wait for his turn. If he used the card instead of becoming aggressive, he was praised for his good behaviour and was rewarded with a visit to the cinema. 
A review of 109 articles evaluating positive behavioural support interventions (see Carr 1999) concluded that $52 \%$ of interventions reduced challenging behaviour by at least 90\% from baseline levels and $68 \%$ by at least $80 \%$. For about two-thirds of the interventions the effect was maintained for between 1 and 24 months. Evidence was also found regarding factors that influence efficacy: interventions were more effective for single than for combinations of behaviours and when they were implemented by the individual's regular carers as opposed to external specialist providers.

LaVigna \& Willis (2012) concluded that positive behavioural support is effective in institutional settings and in the community. They argue that it is cost-effective and applicable to varying levels of severity and frequency of challenging behaviour.

We (A.H. and J.B.) are currently involved in a multicentre cluster randomised trial (NCT01680276) in the UK to investigate the clinical benefits and cost-effectiveness of positive behavioural support.

\section{Pharmacological interventions}

\section{Antipsychotics}

Antipsychotic medications are regularly prescribed to people with intellectual disability and behavioural disorders (Grey 2005). However, there are limited data available on their efficacy in modifying challenging behaviour. One doubleblind randomised controlled trial comparing haloperidol and risperidone with placebo in 86 individuals with aggressive behaviour and intellectual disability found no evidence at 4 weeks that antipsychotics were more effective than placebo (Tyrer 2009). However, another comparing risperidone with placebo in 77 patients did find evidence at 4 weeks supporting the use of risperidone in participants with mild or moderate intellectual disability or borderline intellectual functioning, and DSM-IV disruptive behavioural disorders (Gagiano 2005). Participants assigned to risperidone showed a significantly greater improvement on the primary outcome (Aberrant Behavior Checklist) as well as improvements on secondary outcomes. The trial continued for another 48 weeks as an open-label study where both groups were continued on risperidone, and further improvements were noted.

There is currently insufficient evidence that antipsychotic medication is either helpful or harmful for adults with intellectual disability and challenging behaviour (Brylewski 2004; Deb 2007a,b,c). This is especially salient in light of the findings of a more recent study on the knowledge and experiences of people with intellectual disability receiving antipsychotics (Crossley 2009). Its participants had little knowledge about their medication beyond knowing the dosing regimen and generally accepted the side-effects that they were experiencing. It was noted that this compliance was probably because they were used to relying on other people to make decisions, including those about treatment, on their behalf, trusting them to be better placed to do so.

There is some evidence for the effectiveness of risperidone in addressing challenging behaviour in children with autism spectrum disorder, including those with intellectual disability (Unwin 2011; National Collaborating Centre for Mental Health 2012). In individuals with autism, antipsychotics may reduce the arousal and anxiety contributing to the challenging behaviour. However, National Institute for Health and Care Excellence (NICE) guidelines state that such medications should not be used to treat core symptoms of autism in adults or children (National Collaborating Centre for Mental Health 2012, 2013), although a randomised controlled trial of risperidone $v$. placebo indicated a significant reduction in stereotyped behaviours at 6 months (McDougle 2005). An audit of the prescribing of antipsychotic medication in adults with intellectual disability revealed that increased use of such drugs correlated with severity of intellectual disability and challenging behaviour in the absence of comorbid mental illness (Paton 2011).

\section{Mood stabilisers}

There are two double-blind controlled trials showing beneficial effects of lithium compared with placebo in treating aggression in people with intellectual disability. Tyrer et al (1984) conducted a 5-month crossover trial involving 25 in-patients, where lithium or placebo was added to existing antipsychotic or anticonvulsant treatment. The study found that 17 patients showed improvement in levels of aggression during the lithium phase compared with the placebo phase. Factors associated with a good response included female gender, a history of epilepsy, a low level of aggression pre-treatment, and the presence of overactivity and stereotypical behaviour. Improvements were less likely in males with very frequent aggressive behaviour.

Craft et al (1987), in a study of 42 patients randomised to lithium or placebo, found that $16(73 \%)$ of the 22 receiving lithium showed a reduction in aggression over a 12 -week period. Side-effects were reported in 8 (36\%) of the patients on lithium compared with $4(20 \%)$ on placebo. 
Most of the participants had not responded to other treatments.

Both of these studies have limitations in terms of their sample size, the measures used to assess response to treatment, and lack of follow-up data and applicability in current practice. The participants in the two studies were hospital inpatients, whereas the majority of service users with aggressive behaviour now live in the community, where it is often less practical to initiate lithium. Multicentre randomised controlled trials using lithium are required to provide further evidence of efficacy and safety.

A systematic review found little evidence for the effectiveness of mood stabilisers in the treatment of explosive and intermittent aggression (Jones 2011). Although it found some support of their use in reducing the severity and frequency of aggressive behaviours, this was the case only for phenytoin, lithium and carbamazepine/oxcarbazepine, and not for valproate or levetiracetam. However, several of the studies were subject to bias, and when these were excluded, no significant effect in reducing aggression was found for treatment with mood stabilisers. A major drawback is that the review did not include studies involving people with intellectual disability.

\section{Antidepressants}

Selective serotonin reuptake inhibitors (SSRIs) have been frequently used for the management of challenging behaviour, although the supporting evidence is circumstantial or based on small open-label studies. One review found that antidepressants, SSRIs in particular, produced improvement in aggressive and self-injurious behaviour in people with intellectual disability in less than 50\% of cases (Sohanpal 2007). The effect of antidepressants was most apparent in individuals with an underlying anxiety disorder. However, there is some evidence that fluvoxamine may be effective in reducing challenging behaviour in adults with autism spectrum conditions (OliverAfricano 2009).

Thus, at present there is a paucity of evidence on the effectiveness of pharmacological interventions for challenging behaviour in intellectual disability, with the exception of autism spectrum disorder, where there is limited evidence for the use of antipsychotic medication. Given concerns about the potential for side-effects, further investigation of such treatments is needed.

\section{Current NHS service delivery models}

A locally based service model for the management of challenging behaviour in people with intellectual disability has been recommended by several UK government policies (Department of Health 2007; Commission of Social Care Inspection 2009), but progress towards this has been slow (Allen 2005). The behaviour can usually be managed in a community setting with the help of community intellectual disability teams. For individuals presenting with more severe or ongoing challenging behaviour, input from a specialist challenging behaviour team may be helpful, but service provision does vary in different areas.

Individuals with intellectual disability presenting with severe challenging behaviour that cannot be managed in the community because of the risk to the individual or others will require admission to hospital. If the person has an underlying mental illness, then where possible, admission should be to a generic mental health ward. However, if the needs are more complex, admission to a specialist hospital for people with intellectual disability (an assessment and treatment or A\&T unit), may be required.

Following the exposure of widespread physical and emotional abuse at one A\&T unit, Winterbourne View hospital, the Department of Health (2012) set out a programme to reform these services. Admission should occur only in exceptional circumstances, the reason should be clearly documented and families should be involved in the decision-making process. The time spent in such units should be brief and should focus on the attainment of specific goals. Out-of-area placements should be avoided as they can have deleterious effects on relationships and continuity of care and may contribute to challenging behaviour. Commissioners are expected to work more closely with local service providers to ensure that appropriate local placements and skilled care are available.

\section{Conclusions}

There is very little support for use of pharmacological treatments for people with challenging behaviour and intellectual disability in the absence of coexisting mental illness. However, medication may be required in the presence of high arousal and severe aggressive behaviour. There is emerging interest in behavioural interventions for reducing challenging behaviour, including positive behavioural support, a values-led approach that is person centred. The increasing proliferation of treatment approaches for challenging behaviour and the ongoing improvement in study design, including randomised controlled trials, are cause for optimism regarding the enhancement of evidence-based care for individuals with 
intellectual and developmental disabilities and challenging behaviour.

\section{References}

Allen D, James W, Evans J, et al (2005) Positive behavioural support: definition, current status and future directions. Tizard Learning Disability Review, 10 (2): 4-11.

Berney TP (2000) Autism - an evolving concept. British Journal of Psychiatry, 176: 20-5.

Bijou SW, Baer DM (1978) Behavior Analysis of Child Development. Prentice-Hall.

Bishop S, Lau M, Shapiro S, et al (2004) Mindfulness: a proposed operational definition. Clinical Psychology: Science and Practice, 11: 230-41

Bradshaw J, McGill P, Stretton R, et al (2004) Implementation and evaluation of active support. Journal of Applied Research in Intellectual Disabilities, 17: 139-48.

Brylewski J, Duggan L (2004) Antipsychotic medication for challenging behaviour in people with learning disability (review). Cochrane Database of Systematic Reviews, issue 3: CD000377.

Carr EG, Horner RH, Turnbull AP, et al (1999) Positive Behavior Support for People with Developmental Disabilities: A Research Synthesis. American Association on Mental Retardation.

Carr EG, Dunlap G, Horner RH, et al (2002) Positive behavior support: evolution of an applied science. Journal of Positive Behavior Interventions, 4: 4-16.

Carter M, Driscoll C (2007) A conceptual examination of setting events. Educational Psychology, 27: 655-73.

Commission of Social Care Inspection, Healthcare Commission, Mental Health Act Commission (2009) Commissioning Services and Support for People with Learning Disabilities and Complex Needs: National Report of Joint Review. Commission of Social Care Inspection.

Cooper SA, Smiley E, Allan LM, et al (2009a) Adults with intellectual disabilities: prevalence, incidence and remission of self-injurious behaviour, and related factors. Journal of Intellectual Disability Research, 53: 200-16.

Cooper SA, Smiley E, Jackson A, et al (2009b) Adults with intellectual disabilities: prevalence, incidence and remission of aggressive behaviour and related factors. Journal of Intellectual Disability Research, 53: 21732.

Craft M, Ismail IA, Krishnamurti D, et al (1987) Lithium in the treatment of aggression in mentally handicapped patients: a double-blind trial. British Journal of Psychiatry, 150: 685-9.

Crossley R, Withers P (2009) Antipsychotic medication and people with intellectual disabilities: their knowledge and experiences. Journal of Applied Research in Intellectual Disabilities, 22: 77-86.

Deb S (2007a) The role of medication in the management of behaviour problems in people with learning disabilities. Advances in Mental Health and Learning Disabilities, 1: 26-31.

Deb S, Unwin G (2007b) Psychotropic medication for behaviour problems in people with intellectual disability: a review of the current literature. Current Opinion in Psychiatry, 20: 461-6.

Deb S, Sohanpal SK, Soni R, et al (2007c) The effectiveness of antipsychotic medication in the management of behaviour problems in adults with intellectual disabilities. Journal of Intellectual Disability Research, 51: 766-77.

Department of Health (2007) Services for People with Learning Disabilities and Challenging Behaviour or Mental Health Needs. TSO (The Stationery Office)

Department of Health (2012) Transforming Care: A National Response to Winterbourne View Hospital. Department of Health Review: Final Report. Department of Health.

De Winter CF, Jansen AA, Evenhuis HM (2011) Physical conditions and challenging behaviour in people with intellectual disability: a systematic review. Journal of Intellectual Disability Research, 55: 675-98.
Dodd P, Dowling S, Hollins S (2005) A review of the emotional, psychiatric and behavioural responses to bereavement in people with intellectual disabilities. Journal of Intellectual Disability Research, 49: 537-43.

Durand VM, Crimmins DB (1992) The Motivation Assessment Scale (MAS) Administration Guide. Monaco \& Associates.

Emerson C (1995) Challenging Behaviour: Analysis and Intervention in People with Learning Difficulties. Cambridge University Press.

Emerson E, Kiernan C, Alborz A, et al (2001a) The prevalence of challenging behaviours: a total population study. Research in Developmental Disabilities, 22: 77-93.

Emerson E, Einfield S (2001b) Challenging Behaviour: Analysis and Intervention in People with Learning Difficulties (3rd edn). Cambridge University Press.

Esbenson AJ, Benson BA (2006) A prospective analysis of life events, problem behaviours and depression in adults with intellectual disability. Journal of Intellectual Disability Research, 50: 248-58.

Fox L, Dunlap G, Buschbacher P (2000) Understanding and intervening with children's challenging behavior: a comprehensive approach. In Autism Spectrum Disorders: A Transactional Developmental Perspective (eds AM Wetherby, BM Prizant): 307-31. Brookes Publishing.

Gagiano C, Read S, Thorpe L, et al (2005) Short- and long-term efficacy and safety of risperidone in adults with disruptive behavior disorders. Psychopharmacology, 179: 629-36.

Grey IM, Hastings RP (2005) Evidence-based practices in intellectual disability and behaviour disorders. Current Opinion in Psychiatry, 18: 469-75

Hanley GP, Iwata BA, McCord BE (2003) Functional analysis of problem behavior: a review. Journal of Applied Behavior Analysis, 36: 147-85.

Harper S, Webb T, Rayner K (2013) The effectiveness of mindfulnessbased interventions for supporting people with intellectual disabilities: a narrative review. Behavior Modification, 37: 431-53.

Hassiotis AA, Hall I (2008) Behavioural and cognitive-behavioural interventions for outwardly-directed aggressive behaviour in people with learning disabilities. Cochrane Database of Systematic Reviews, issue 3: CD003406.

Hassiotis A, Robotham D, Canagasabey A, et al (2009) Randomized, single-blind, controlled trial of a specialist behaviour therapy team for challenging behaviour in adults with intellectual disabilities. American Journal of Psychiatry, 166: 1278-85.

Hassiotis A, Canagasabey A, Robotham D, et al (2011) Applied behaviour analysis and standard treatment in intellectual disability: 2-year outcomes. British Journal of Psychiatry, 198: 490-1.

Jones E, Felce D, Lowe K, et al (2001) Evaluation of the dissemination of active support training and training trainers. Journal of Applied Research in Intellectual Disabilities, 14: 79-99.

Jones RM, Arlidge J, Gillham R, et al (2011) Efficacy of mood stabilisers in the treatment of impulsive or repetitive aggression: systematic review and meta-analysis. British Journal of Psychiatry, 198: 93-8.

LaVigna GW, Willis TJ (2012) The efficacy of positive behavioural support with the most challenging behaviour: the evidence and its implications. Journal of Intellectual \& Developmental Disability, 37: 185-95.

Lowe K, Allen D, Jones E (2007) Challenging behaviours: prevalence and topographies. Journal of Intellectual Disability Research, 51: 625-36.

McClintock K, Hall S, Oliver C (2003) Risk markers associated with challenging behaviours in people with developmental disabilities: a metaanalytic study. Journal of Intellectual Disabilities Research, 47: 405-16. McDougle CJ, Scahill L, Aman MG, et al (2005) Risperidone for the core symptom domains of autism: results from the study by the Autism Network of the Research Units on Pediatric Psychopharmacology. American Journal of Psychiatry, 162: 1142-8.

Moss S (1999) Assessment and conceptual issues. In Psychiatric and Behavioural Disorders in Development Disabilities and Mental Retardation (ed N Bouras): 18-37. Cambridge University Press.

Moss S, Emerson E, Kiernan C, et al (2000) Psychiatric symptoms in adults with learning disability and challenging behaviour. British Journal of Psychiatry, 177: 452-6.

\section{MCO answers}

1 a 2 e 3 b $4 d \quad 5$ e 
National Collaborating Centre for Mental Health (2012) Autism: The NICE Guideline on Recognition, Referral, Diagnosis and Management of Adults on the Autism Spectrum (National Clinical Guideline Number 142). British Psychological Society \& Royal College of Psychiatrists.

National Collaborating Centre for Mental Health (2013) Autism: The Management and Support of Children and Young People on the Autism Spectrum (National Clinical Guideline Number 170). NICE.

Oliver-Africano P, Murphy D, Tyrer P (2009) Aggressive behaviour in adults with intellectual disability: defining the role of drug treatment. CNS Drugs, 23: 903-13.

O'Neill R, Horner R, Albin R, et al (1997) Functional Assessment and Programme Development for Problem Behaviour: A Practical Handbook. Brooks/Cole Publishing.

Palucka AM, Nyhus N, Lunsky Y (2003) Aggression as a symptom of mood destabilization in pervasive developmental disorders. Journal on Developmental Disabilities, 10: 101-5.

Paton C, Flynn A, Shingleton-Smith A, et al (2011) Nature and quality of antipsychotic prescribing practice in UK psychiatry of intellectual disability services. Journal of Intellectual Disability Research, 55: 665-74.

Poppes P, van der Putten AJJ, Vlaskamp C (2010) Frequency and severity of challenging behaviour in people with profound intellectual disability and multiple disabilities. Research in Developmental Disabilities, 31: 1269-75.

Reiss S, Levitan G, Szysko J (1982) Emotional disturbance and mental retardation: diagnostic overshadowing. American Journal of Mental Deficiency, 86: 567-74.

Royal College of Psychiatrists (2007) Challenging Behaviour: A Unified Approach (College Report CR144). Royal College of Psychiatrists.

Sohanpal SK, Deb S, Thomas C, et al (2007) The effectiveness of antidepressant medication in the management of behaviour problems in adults with intellectual disabilities: a systematic review. Journal of Intellectual Disability Research, 51: 750-65.

Stancliffe RJ, Jones E, Mansell J, et al (2008) Active support: a critical review and commentary. Journal of Intellectual and Developmental Disability, 33: 196-214.
Thakker Y, Bamidele K, Ali A, et al (2012) Mental health and challenging behaviour: an overview of research and practice. Advances in Mental Health and Intellectual Disabilities, 6: 249-58.

Toogood S, Drury G, Gilsenan K, et al (2009) Establishing a context to reduce challenging behaviour using procedures from active support: a clinical case example. Tizard Learning Disability Review, 14: 29-36.

Tyrer SP, Walsh F, Edwards DE, et al (1984) Factors associated with a good response to lithium in aggressive mentally-handicapped subjects. Progress in Neuro-Psychopharmacology \& Biological Psychiatry, 8: $751-5$.

Tyrer P, Bajaj P (2005) Nidotherapy: making the environment do the therapeutic work. Advances in Psychiatric Treatment, 11: 232-8.

Tyrer P, Kramo K (2007) Nidotherapy in practice. Journal of Mental Health, 16: 117-29.

Tyrer P, Oliver-Africano P, Romeo R, et al (2009) Neuroleptics in the treatment of aggressive challenging behaviour for people with intellectual disabilities: a randomized controlled trial (NACHBID). Health Technology Assessment, 13 (21): 1-54.

Unwin GL, Deb S (2008) The use of medication for the management of behavior problems among adults with intellectual disability: a clinician's consensus survey. American Journal on Mental Retardation, 113: $19-31$.

Unwin GL, Deb S (2011) Efficacy of atypical antipsychotic medication in the management of behaviour problems in children with intellectual disabilities and borderline intelligence: a systematic review. Research in Developmental Disabilities, 32: 2121-33.

Vissers LE, de Vries BB, Veltman JA (2010) Genomic microarrays in mental retardation: from copy number variation to gene, from research to diagnosis. Journal of Medical Genetics, 47: 289-98.

Willner P, Rose J, Jahoda A, et al (2013) A cluster randomised controlled trial of a manualised cognitive behavioural anger management intervention delivered by supervised lay therapists to people with intellectual disabilities. Health Technology Assessment, 17 (21): $1-173$.

\section{MCQs}

Select the single best option for each question stem

1 The prevalence of challenging behaviour in adults with intellectual disability living in the community is estimated to be:
a $3-10 \%$
b $60-80 \%$
c $10-20 \%$
d $20-30 \%$
e $40-50 \%$

2 Challenging behaviour can be caused by:

a medication side-effects

b mental illness

c negative life events

d pervasive developmental disorder

e all of the above.

\section{The medication most often used in routine 5 Functional analysis:} care to manage aggressive challenging behaviour is:

a carbamazepine

b risperidone

c fluvoxamine

d haloperidol

e lamotrigine.

4 Evidence suggests that the first-line treatment for challenging behaviour unrelated to mental illness is:

a antipsychotics

b nidotherapy

c active support

d positive behavioural support

e none of the above. a is an important component of behavioural approaches to challenging behaviour

b is a component of positive behavioural support

c uses $\mathrm{ABC}$ charts

$d$ is used to generate hypotheses about the purpose of a behaviour

e all of the above. 